\title{
Análise e caracterização das questões das provas da Olimpíada Brasileira de Física ${ }^{+*}$
}

\author{
João Paulo Casaro Erthal ${ }^{1}$ \\ Ramón Giostri Campos ${ }^{2}$ \\ Thays Ferreira Souza ${ }^{3}$ \\ Juliana de Souza Oliveira ${ }^{4}$ \\ Departamento de Química e Física - UFES \\ Alegre - ES
}

\section{Resumo}

No Brasil, anualmente, são organizadas e praticadas olimpíadas escolares em diversas áreas do conhecimento, tais como: língua portuguesa, matemática, biologia, física, entre outras. A Olimpíada Brasileira de Física $(O B F)$ tem como objetivo despertar e estimular nos estudantes o interesse pela física, proporcionando desafios e incentivando-os a seguir carreiras científicas e tecnológicas. Este trabalho visa investigar os conteúdos exigidos nas provas da OBF e a forma como estes são abordados, com a finalidade de traçar um perfil das provas da $O B F$, aplicadas aos estudantes do ensino médio. Para isso, realizou-se uma análise das questões das provas do período de 1999 a 2013, distribuindo os conteúdos das questões das provas em seis áreas de conhecimento da física: mecânica, ondulatória, física térmica, eletromagnetismo, óptica geométrica e física moderna. Após a análise foram construídos gráficos que auxiliaram a identificar peculiaridades destas provas. Os resultados mostram uma evolução no perfil da prova, que atualmente possui uma abordagem mais contextualizada e interdisciplinar quando comparada às edições

\footnotetext{
Analysis and characterization of the issues of Brazilian Physics Olympiad Exams

* Recebido: fevereiro de 2014.

Aceito: julho de 2014.

1 E-mail: jperthal@gmail.com

2 E-mail: ramon_giostri@yahoo.com.br

3 E-mail: ferreira.s.thays@gmail.com

${ }^{4}$ E-mail: jusouza_oliveira20@hotmail.com
} 
anteriores, em consonância ao que está descrito nos documentos oficiais da educação brasileira.

Palavras-chave: Olimpíada Brasileira de Física. Análise de questões. Perfil das provas.

\begin{abstract}
Every year in Brazil, School Olympics are organized including various knowledge areas, such as: Portuguese Language, Mathematics, Biology, Physics, and others. The Brazilian Physics Olympiad (OBF) intends to stimulate students' interest in Physics, by challenging and encouraging them to pursue careers in science and technology. This paper aims to investigate the contents that are present in the OBF exams and how these are addressed, in order to draw a profile of the exam that is applied to high school students. For this purpose, an analysis of the questions from the exam, from the period between 1999 and 2013, is carried out, and the contents of the questions are separated in six Physics fields: Mechanics, Wave, Thermal Physics, Electromagnetism, Geometric Optics and Modern Physics. Afterwards, graphics are developed in order to identify peculiarities of these tests. The results present positive changes in the profile of the test, which has a more contextualized and interdisciplinary approach, compared to previous editions, in line with the official documents of the Brazilian education.
\end{abstract}

Keywords: The Brazilian Physics Olympiad. Analysis of questions. Profile of the exam.

\title{
I. Introdução
}

Nas últimas décadas, várias áreas do conhecimento vêm desenvolvendo e aprimorando competências específicas por meio de olimpíadas científicas, dentre as quais podemos destacar as olimpíadas de astronomia, língua portuguesa, história, matemática, química, ciências júnior, informática, biologia e física (ERTHAL et al., 2013). De acordo com Ostermann e Rezende (2012), no Brasil algumas dessas competições são patrocinadas pelo Governo Federal enquanto que outras, como a OBF, por exemplo, vêm sendo organizadas por sociedades específicas, contando, em certos casos, com apoio de órgãos de fomento como o Conselho Nacional de Desenvolvimento Científico e Tecnológico (CNPq).

Mundialmente falando, as olimpíadas de física começaram em 1960, quando um pequeno grupo de três professores de física da Europa decidiu organizar uma competição nesse 
formato. Em 1962 foi realizada a primeira Olimpíada Internacional de Física (OIF), que ocorreu em Varsóvia na Polônia (VIANNA et al., 2000).

No Brasil, as primeiras olimpíadas de física ocorreram no ano de 1985 no Estado de São Paulo. Estas olimpíadas foram organizadas por professores da Academia de Ciências do Estado de São Paulo (MARIN; PINO JUNIOR, 2008). Em 1986, foi realizada de forma independente a Olimpíada Paranaense de Física, e em 1994 outros estados como Ceará, Paraíba e Minas Gerais começaram a realizar olimpíadas de física regionais (VIANNA et al., 2000). Em 1995, o Centro de Divulgação Científica e Cultural do Instituto de Física de São Carlos, da Universidade de São Paulo, retomou a realização das olimpíadas no estado.

Em 1998, a Sociedade Brasileira de Física passou a organizar o evento, sendo que, nesse ano, participaram de forma experimental os estados da Bahia, Goiás, Pará, Pernambuco, Rio de Janeiro e São Paulo. Após essa fase de estruturação de um modelo para essa competição, teve início, em 1999, a Olimpíada Brasileira de Física, com participação de 18 estados brasileiros e um total de 13 mil estudantes.

A OBF é realizada em três fases. A primeira fase ocorre no mês de maio na escola do estudante participante. A segunda fase é realizada em agosto em locais determinados pelo Coordenador Estadual e dela participam os estudantes que atingiram o número mínimo de acertos na primeira fase, sendo este definido pela Comissão da Olimpíada Brasileira de Física. Se o número de estudantes classificados de uma determinada escola for menor que três em alguma série, o sistema de seleção completará este número indicando os alunos com a maior nota abaixo da nota mínima. Participam da terceira fase os estudantes que atingirem na fase anterior a nota mínima estipulada pela comissão organizadora, garantindo-se a cada Estado o número mínimo de um estudante por série. Essa etapa é cumprida em outubro ou novembro sendo realizada na sede da Coordenação Estadual. As questões das provas teóricas da primeira fase são objetivas e as da segunda e terceira fases são discursivas. Cabe salientar que na terceira fase o participante realiza ainda uma prova prática, exceto na prova do terceiro ano do ensino médio (SOCIEDADE BRASILEIRA DE FÍSICA, 2014).

A Olimpíada Brasileira de Física tem como objetivo despertar e estimular o interesse pela física, proporcionando desafios aos estudantes, buscando aproximar a universidade do ensino médio, identificando os estudantes talentosos em física e preparando-os para as Olimpíadas Internacionais de Física para, desta forma, incentivá-los a seguir carreiras científicas e tecnológicas (SOCIEDADE BRASILEIRA DE FÍSICA, 2014).

As questões das provas podem servir como material de auxílio ao professor para o ensino e avaliação da aprendizagem dos alunos, uma vez que, ele irá dispor de questões bem elaboradas e diversificadas. Em cinco edições analisadas (2007, 2010, 2011, 2012 e 2013) a OBF traz provas contextualizadas e baseadas em temas específicos, procurando ressaltar o sentido da física como visão geral de mundo, como cultura em seu sentido mais amplo, exibindo uma forma diferenciada de abordar os conteúdos dessa ciência. 
De acordo com Vianna e Siqueira (2004) em alguns anos a OBF, pode proporcionar informações de interesse para o ensino e aprendizagem da física, já que as provas podem auxiliar a encontrar as dificuldades dos estudantes, contribuindo para a criação do novo ensino médio. Em vista disso, este trabalho visa investigar os conteúdos e a forma como estes são abordados com a finalidade de traçar um perfil das provas da Olimpíada Brasileira de Física, aplicadas aos estudantes do ensino médio.

\section{Desenvolvimento}

Esse trabalho foi iniciado com a busca pelas provas da OBF desde o início de sua realização. Foram obtidas as provas dos anos de 1999 até 2013. Por meio de uma análise minuciosa de todas as questões dessas provas, foi possível verificar quais os conteúdos mais enfatizados e como estes são abordados. Também foram observadas eventuais mudanças no formato das provas olímpicas ao longo dos anos.

Cada questão foi analisada e categorizada de acordo com os conteúdos e conhecimentos exigidos dos alunos para a resolução, tendo como base a forma como os conteúdos são frequentemente divididos nos livros didáticos do ensino médio. As categorias foram: mecânica, física térmica, óptica geométrica, ondulatória, eletromagnetismo e física moderna.

Foram originados três blocos de análise, segundo características comuns entre as provas de diferentes anos. Na sequência foram gerados gráficos de acordo com características comuns entre as provas. Algumas questões catalogadas foram contabilizadas mais de uma vez, pois abordaram mais de uma área da física. A seguir serão apresentados e discutidos os resultados obtidos.

\section{II.1 Primeiro bloco de análise: prova do ano de 1999}

A prova do ano de 1999 foi constituída apenas de duas fases, sendo a única com essa característica. Devido a esse fato, ela constitui o primeiro bloco de análise deste trabalho.

Neste ano algumas questões retratam circunstâncias conhecidas pelos estudantes brasileiros, relacionadas a jogos esportivos, meninos andando de skate e situações contidas em filmes de ficção científica. As questões exigiam que os estudantes soubessem trabalhar com formalismos matemáticos e literais, além de analisar gráficos, com pouca ênfase sendo dada ao domínio de conceitos físicos. A seguir temos um exemplo de questão da primeira fase para o $1^{\circ}$ e $2^{\circ}$ anos do ensino médio, que mostra a utilização de um contexto conhecido pelos alunos: 
Michael Jordan, o famoso jogador de basketball, para "enterrar uma bola" realiza um salto cujo "tempo de voo" é de 0,80 segundos. O tempo de voo é o intervalo de tempo no qual o atleta fica no ar, sem tocar os pés no chão.

a) $O$ "Tempo de voo" depende da componente vertical da velocidade, ou de sua componente horizontal? Justifique sua resposta.

b) Qual a altura máxima que este jogador, consegue atingir?

Em relação aos conteúdos das provas do ano de 1999, a maior parte das questões abordou os conteúdos de mecânica. Os conteúdos de óptica geométrica e física térmica foram pouco requisitados tanto nas provas para o $1^{\circ} \mathrm{e} 2^{\circ}$ anos, quanto nas provas para o $3^{\circ}$ ano.

Para os alunos do terceiro ano os conteúdos de eletromagnetismo e ondulatória apareceram medianamente e os conteúdos relacionados à física moderna não foram cobrados. Já para os alunos do $1^{\circ}$ e $2^{\circ}$ anos não apareceram questões relacionadas ao conteúdo de ondulatória, como pode ser observado nos gráficos a seguir:

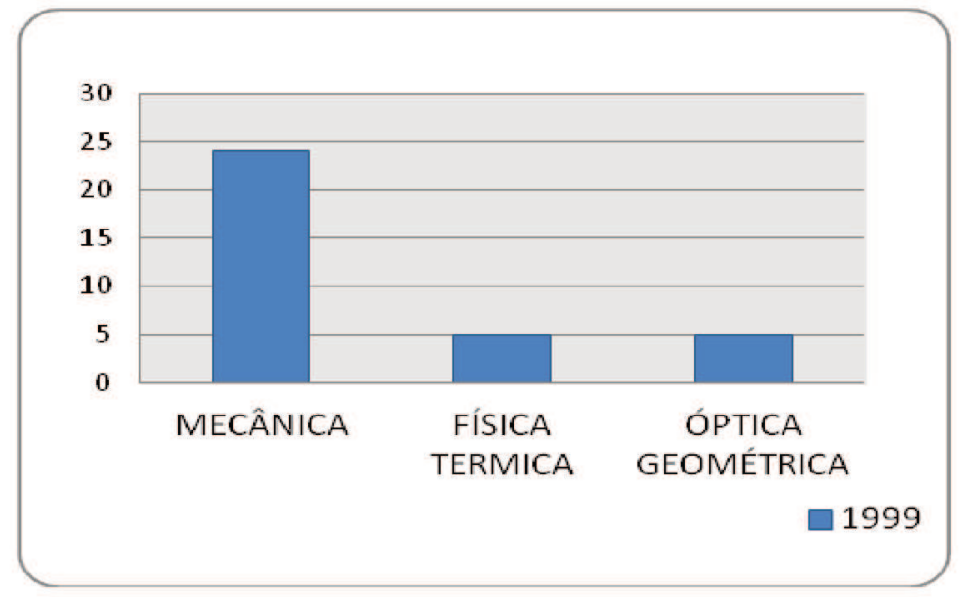

Fig. 1 - Gráfico da prova para o $1^{\circ}$ e $2^{\circ}$ anos do ensino médio de 1999.

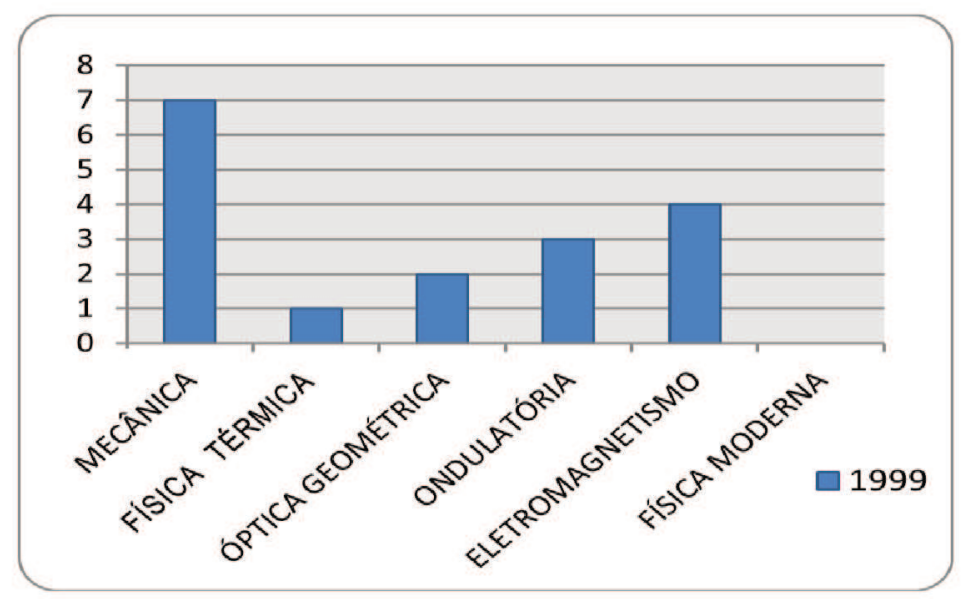

Fig. 2 - Gráfico da prova para $3^{\circ}$ ano do ensino médio de 1999. 
A mecânica é uma área extensa da física sendo geralmente discutida e estudada no primeiro ano do ensino médio. Seu conhecimento é essencial para o estudo dos principais conteúdos do segundo e do terceiro ano, sendo que esse fato pode justificar a maior quantidade de questões de mecânica nos resultados das análises do ano de 1999.

\section{II.2 Segundo bloco de análise: provas dos anos de 2000 a 2009 exceto 2007}

A partir do ano de 2000 a OBF passou a ter a terceira fase e o número de questões aumentou significativamente. Em vista disso, essas provas originaram o segundo bloco de análise. Nas provas pode-se observar que foi demasiadamente esperado que o aluno soubesse analisar gráficos e relacionar grandezas. Muitas questões tiveram enfoque na resolução de problemas com abordagem rigorosamente matemática e pura aplicação de formalismos, enquanto que outras questões exigiam que o aluno dominasse com clareza os conceitos físicos. As provas dos anos 2000, 2002 e 2005 foram as que tiveram maior percentual de questões conceituais sendo exigidas, com 24,49\%, 26,68\%, 25,47\% respectivamente. Isso mostra uma tendência diferenciada dessas provas quando comparadas a de 1999 , a qual teve apenas $12,50 \%$ de questões que não necessitavam de cálculos para sua resolução. A seguir, são apresentados os gráficos para as provas desse bloco de análise.

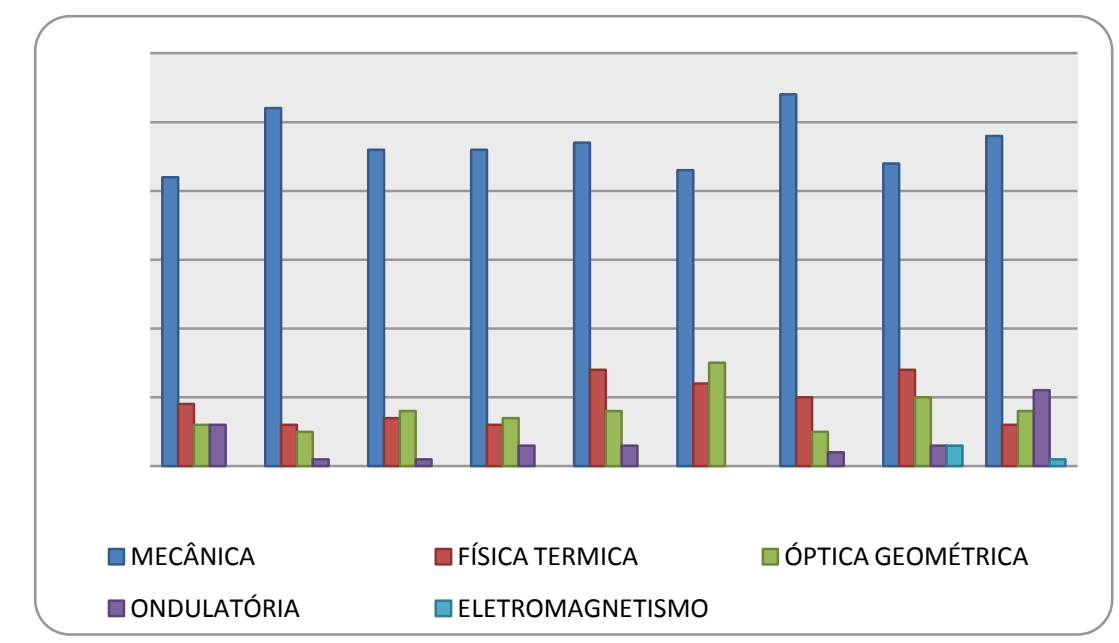

Fig. 3 - Gráfico das provas para o $1^{\circ}$ e $2^{\circ}$ anos do ensino médio de 2000 á 2009 exceto 2007. 


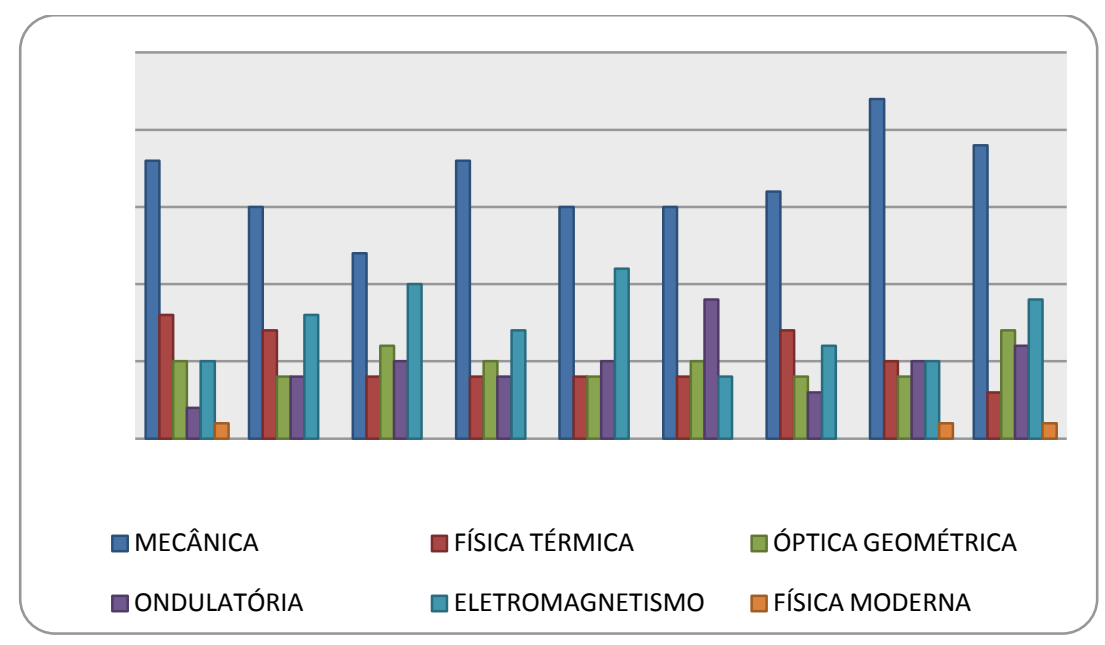

Fig. 4 - Gráfico das provas para o $3^{\circ}$ ano do ensino médio de 2000 á 2009 exceto 2007.

A partir do ano de 2006 as provas da OBF passaram a abranger os alunos do último ano do ensino fundamental, porém, nossa análise se restringiu as provas destinadas ao ensino médio. Algumas provas eram conjuntas, ou seja, eram utilizadas por alunos de séries diferentes. Nessas provas algumas questões deveriam ser feitas exclusivamente pelos estudantes de uma série especifica, sendo que a partir de 2008 algumas provas para o primeiro ano do ensino médio começaram a ser utilizadas em parte pelos estudantes do nono ano do ensino fundamental. Essas restrições eram explicadas nos cabeçalhos de cada prova.

Observou-se que conteúdos relacionados à física moderna apareceram apenas nas provas para os alunos do $3^{\circ}$ ano do ensino médio nos anos 2000, 2008 e 2009, mesmo assim em número bastante reduzido. Isso mostra que apesar do ensino de física moderna ser defendido por pesquisadores e de possuírem extrema importância para compreensão de tecnologias atuais, esses conteúdos não estão presentes nos instrumentos de avaliação para esse público, o que pode estar relacionado à raríssima abordagem do tema em salas de aula.

Seguindo a tendência do primeiro bloco de análise, tem-se a predominância dos conteúdos de mecânica nas questões dessas provas.

\section{II.3 Terceiro bloco de análise: provas dos anos de 2007, 2010, 2011, 2012 e 2013}

Nestes anos as provas da OBF foram baseadas em temas específicos e por isso foi criado o terceiro bloco de análise.

A prova olímpica de 2007 teve como tema o "Motor Múltiplo Híbrido" que foi lançado pela Toyota em 1997. O estudo sobre o funcionamento desse motor envolve conceitos de física como mecânica, termodinâmica e eletromagnetismo, os quais foram abordados nas questões de forma contextualizada. As questões dessa prova eram, em geral, relacionadas diretamente com o tema norteador, sendo que algumas exigiam que o aluno extraísse informações diretamente do texto dado.

A seguir é apresentado um recorte do tema da primeira fase da prova de 2007: 
A concepção do modelo PRIUS da Toyota é inovadora. Seu Motor Múltiplo Híbrido, que é uma tradução livre de Hybrid Synergy Drive, sintetiza o conhecimento da Física até o fim do século XIX: a Mecânica Clássica, a Termodinâmica e o Eletromagnetismo. O lançamento desse modelo no mercado ocorre devido à existência de um produto típico do século XX, a central eletrônica computadorizada, que controla o Motor de Combustão Interna (MCI) e dois Motores Eletromagnéticos /Geradores, MEG-1 e MEG-2, os quais podem ser usados, conforme a situação, de forma independente ou simultânea.

Em 2010 a prova teve como tema central "Os Cientistas". As provas deste ano abordavam de uma forma resumida a vida e obra de alguns cientistas, em particular cientistas que tiveram grande contribuição para a física, como Galileu Galilei, Johannes Kepler, Isaac Newton, Ludwig Eduard Boltzmann, James Clerk Maxwell e Enrico Fermi.

A seguir é apresentado um recorte do texto sobre um cientista na primeira fase da prova de 2010:

Isaac Newton (1643-1727): Cientista inglês, mais reconhecido como físico e matemático, embora tenha sido também astrônomo, alquimista, filósofo natural e teólogo. Sua obra, Philosophiae Naturalis Principia Mathematica, é considerada uma das mais influentes em História da ciência. Publicada em 1687, esta obra descreve a lei da gravitação universal e as três leis de Newton, que fundamentaram a mecânica clássica. Ao demonstrar a consistência que havia entre o sistema por si idealizado e as leis de Kepler do movimento dos planetas, foi o primeiro a demonstrar que o movimento de objetos, tanto na Terra como em outros corpos celestes, são governados pelo mesmo conjunto de leis naturais. O poder unificador de suas leis era centrado na revolução científica, no avanço do heliocentrismo e na difundida noção de que a investigação racional pode revelar o funcionamento mais intrínseco da natureza. Entre 1670 e 1672 trabalhou intensamente em problemas relacionados com a óptica e a natureza da luz...

"A Física e o Corpo Humano" foi o tema da prova do ano de 2011, na qual os estudantes demonstraram seus conhecimentos físicos a partir de questões envolvendo conceitos sobre o funcionamento do corpo humano. Dessa forma, foi possível relacionar a física com outras áreas de estudo como a medicina, biologia, química, dando um caráter interdisciplinar para várias questões.

A seguir tem-se um recorte de um texto utilizado na primeira fase da prova de 2011: 
Le Parkour salta do anonimato e cai nas graças dos jovens aventureiros. Se você já viu um sujeito escalando muros ou torres elétricas ele pode não ser um ladrão, um pichador ou simplesmente um maluco que não tem amor à vida. Na verdade esse rapaz pode ser um amante do Le Parkour, a nova febre entre os praticantes de exercícios. Le Parkour significa "O Percurso" e tem esse nome em francês porque o seu criador vem de lá. David Belle herdou do pai e do avô bombeiros a paixão por aventura e situações de aparente perigo. A partir daí tornou isso um esporte e um meio de ganhar a vida...

"Olimpíadas de Londres - A Física e os Esportes” foi o tema da prova de 2012, as questões das provas deste ano relacionaram a prática de esportes como: futebol, atletismo, ciclismo, natação, nado sincronizado, entre outros, com vários conteúdos de física com textos introdutórios. Estas provas foram conjuntas para o primeiro e segundo ano em todas as fases, tendo uma quantidade menor de questões relacionadas à mecânica se comparadas às provas dos anos anteriores. Houve uma melhor distribuição na quantidade de questões sobre física térmica, ondulatória e eletromagnetismo, porém apenas uma questão exigia o domínio de conhecimentos relacionados à física moderna.

A seguir é apresentado um exemplo de questão da primeira fase da prova de 2012:

Numa competição de Nado Sincronizado, uma das atletas se encontra com a cabeça a $50 \mathrm{~cm}$ abaixo da superfície da água, enquanto outra se encontra à sua frente com os pés sob a água, a uma profundidade de $40 \mathrm{~cm}$. A menor distância entre as atletas para que a que está com a cabeça dentro d'água consiga ver a imagem dos pés da outra refletida na superfície da água é aproximadamente:
(a) $0 \mathrm{~cm}$
(b) $41 \mathrm{~cm}$
(c) $51 \mathrm{~cm}$
(d) $92 \mathrm{~cm}$

(e) A atleta não conseguirá ver a imagem dos pés da outra refletida na superfície da água.

As provas aplicadas no ano de 2013 tiveram por tema "O Universo em Escala Planetária”. Estas provas trouxeram pequenos textos introdutórios sobre curiosidades de caráter histórico científico abordando conteúdos a partir dos quais os conhecimentos dos estudantes eram exigidos.

A seguir é apresentada uma questão da primeira fase da prova de 2013: 
Devido principalmente à topografia de Marte, muitos cientistas acreditam que há bilhões de anos poderia ter havido água naquele planeta. Outras evidências mostram o contrário. $O$ debate se acirrou quando o veículo exploratório Opportunity encontrou um mineral que seria gipsita. Na Terra a gipsita é encontrada em regiões onde houve evaporação de água. A razão para o intenso debate é que se de fato algum dia houve água em Marte, a chance de ter havido vida aumenta muito. A pressão atmosférica média em Marte é 600Pa (0,006atm) e a temperatura na superfície do planeta varia entre $-143^{\circ} \mathrm{C}$ e $27^{\circ} \mathrm{C}$. Considere agora a figura que mostra o diagrama de fase da água pura. A que temperaturas a água na pressão de latm muda, respectivamente, do estado sólido para o líquido e do líquido para o gasoso?
(a) $10^{\circ} \mathrm{Ce} 401^{\circ} \mathrm{C}$
(b) $401^{\circ} \mathrm{C}$ e $0^{\circ} \mathrm{C}$
(c) $0^{\circ} \mathrm{C}$ e $401^{\circ} \mathrm{C}$
(d) $100^{\circ} \mathrm{Ce} 0^{\circ} \mathrm{C}$
(e) $0^{\circ} \mathrm{C}$ e $100^{\circ} \mathrm{C}$

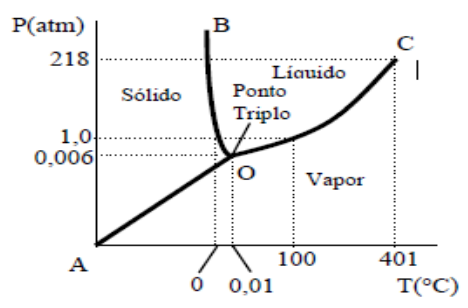

Na sequência, são apresentados os gráficos com o quantitativo de questões e as consecutivas áreas da física segundo a qual essas foram classificadas para esse bloco de análise.

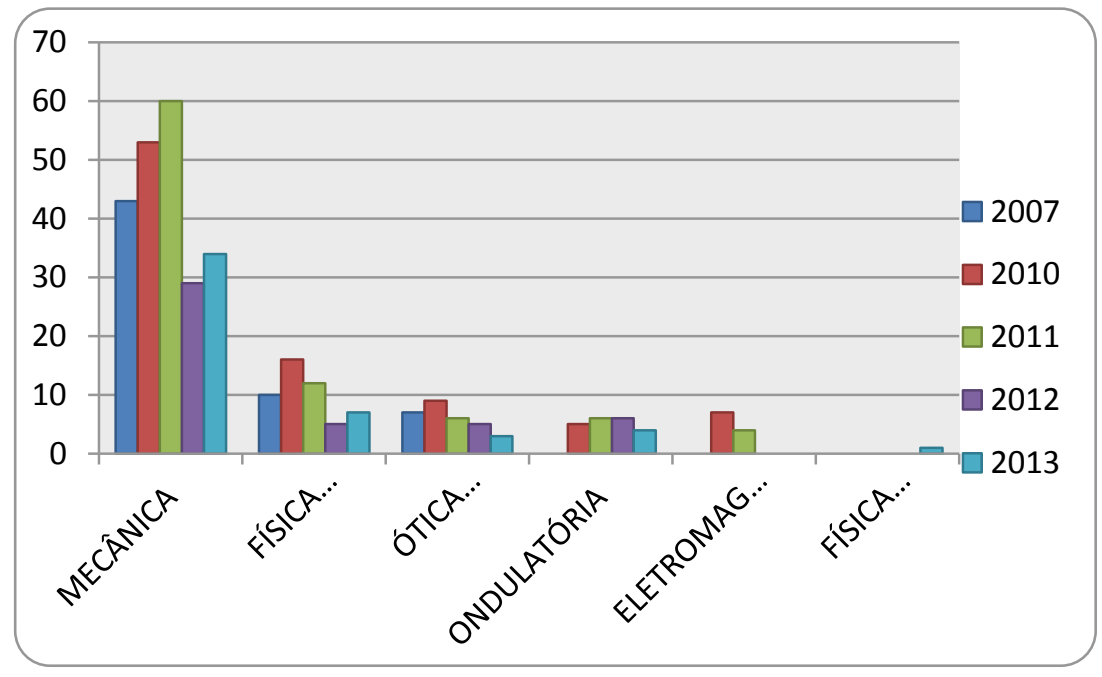

Fig. 5 - Gráfico das provas para o $1^{\circ}$ e $2^{\circ}$ anos do ensino médio nos anos 2007, 2010, 2011, 2012 e 2013. 


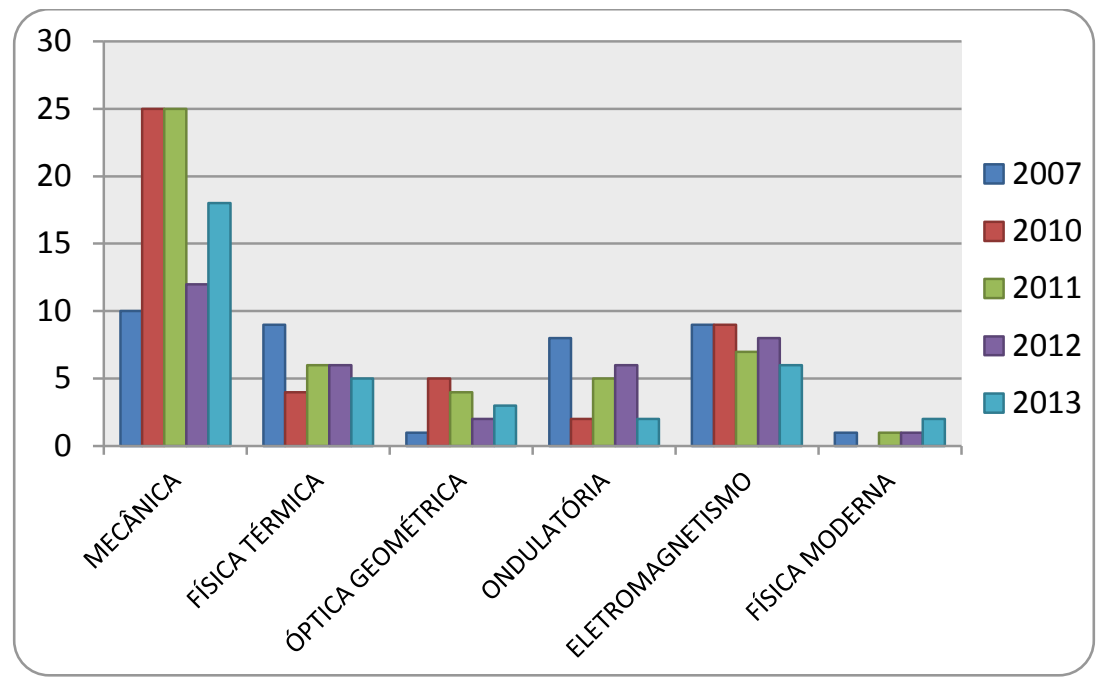

Fig. 6 - Gráfico das provas para o $3^{\circ}$ ano do ensino médio nos anos 2007, 2010, 2011, 2012 e 2013.

Um aspecto importante a ser frisado é que ao trazer questões contextualizadas, as provas da OBF não apenas exigem que o aluno demonstre seus saberes, mas também, ajudam a expor ao estudante que a física é utilizada nas mais diversas áreas do conhecimento. Dessa forma, a realização das provas da OBF se torna, ao mesmo tempo, uma experiência de verificação e de construção do conhecimento do aluno.

Os resultados mostram que nas provas desse bloco de análise, ocorreu uma melhor distribuição dentre os ramos da física exigidos e também um aumento na quantidade de questões de física moderna em relação aos outros blocos analisados.

\section{Considerações finais}

Com a análise das provas verificou-se que com exceção da prova de 1999 todas as provas até o ano de 2013 apresentam três fases, na qual a primeira fase é uma prova com questões objetivas. A segunda fase de alguns anos teve provas com questões discursivas e questões objetivas e em outros anos apenas provas com questões discursivas. A terceira fase apresentou apenas questões discursivas e uma prova experimental para os alunos do primeiro e segundo anos.

Em relação ao modelo de questão, verificou-se que em sua primeira edição, no ano de 1999, a maior parte das questões exigia massivamente a utilização de formalismos matemáticos, como a questão apresentada a seguir: 
Um objeto localiza-se a uma distância $x$, à esquerda de uma lente com distância focal $f_{1}=-6 \mathrm{~cm}$. Uma segunda lente, com distância focal $f_{2}=+12 \mathrm{~cm}$, é colocada à direita da primeira, a uma distância de $8 \mathrm{~cm}$ da lente.

a) Para que distância $x$ a imagem final do objeto estará muito distante da segunda lente?

b) Caracterize a imagem do objeto devido à primeira lente.

Nos anos de 2000, 2001, 2002, 2003, 2004, 2005, 2006, 2008 e 2009, as questões que necessitavam da aplicação de formalismos matemáticos para sua resolução continuaram presentes em grande quantidade, porém as provas tiveram um acréscimo na quantidade de questões conceituais e literais. Talvez esse aumento se deva a difusão do conhecimento das orientações de documentos oficiais que não existiam ou que não eram amplamente difundidas em 1999. A seguir tem-se um exemplo de questão conceitual referente ao segundo bloco de análise:

Se você, ao se olhar através de um espelho côncavo, vir sua imagem direita e maior, então: a) A imagem é real e você se encontra entre o foco e o centro de curvatura do espelho.

b) A imagem é real e você se encontra entre o centro e o infinito.

c) A imagem é virtual e você se encontra entre o vértice e o foco do espelho.

d) A imagem é real e você se encontra entre o vértice e o foco do espelho.

e) A imagem é virtual e você se encontra exatamente no centro de curvatura do espelho.

As provas dos anos de 2007, 2010, 2011, 2012 e 2013 foram feitas baseadas em temas, exigindo dos alunos maior capacidade de interpretação e abstração, esperando que o aluno relacionasse seus saberes, o que proporcionou ao estudante uma visão mais geral das aplicações do conhecimento, como se observa na seguinte questão:

"A catarata é uma patologia dos olhos que consiste na opacidade parcial ou total do cristalino ou de sua cápsula. Pode ser desencadeada por vários fatores, como traumatismo, idade, Diabetes mellitus, uveítes, uso de medicamentos, etc. Tipicamente apresenta-se como embaçamento visual progressivo que pode levar a cegueira ou visão subnormal." É muito comum o desenvolvimento de catarata em idosos, sendo necessária intervenção cirúrgica. No desenvolvimento inicial da catarata relacionada à idade a magnificação das lentes (cristalino) pode ser aumentada causando miopia; o gradual amarelamento e o aumento de opacidade da lente podem ocasionar redução da percepção do azul.

De acordo com o texto e seus conhecimentos sobre ótica geométrica é correto afirmar que:

(a) A catarata implica na diminuição da intensidade de luz detectada na retina.

(b) O indivíduo com catarata enxerga apenas algumas cores devido à lesão no cristalino.

(c) O amarelamento do cristalino se deve ao fato de ocorrer maior absorção do amarelo.

(d) A catarata implica no aumento da intensidade de luz detectada na retina.

(e) Em alguns casos a catarata ocasiona aumento da distância focal do olho afetado. 
As questões mostradas anteriormente abordam o conteúdo de ótica geométrica sendo que cada uma pertence a um dos três blocos de análise deste trabalho. É notória a evolução na elaboração do enunciado das questões e no enfoque de cada uma, tendo a de 1999 sua resolução atrelada a conhecimentos matemáticos, a de 2005 exigindo conhecimentos conceituais em sua resposta e a de 2011, com uma evolução na contextualização, demandando conhecimentos interdisciplinares para a resolução.

Em relação ao modelo de prova, verificou-se que as provas se intercalam com fases em que o primeiro e o segundo ano, ou o segundo e o terceiro ano, realizam a mesma prova, porém não respondem na íntegra as mesmas questões. Em algumas dessas provas, os estudantes de uma série específica devem responder a questões exclusivas, enquanto que em outras provas, os estudantes podem escolher, dentre um número limitado, quais questões irão responder.

No que tange à divisão dos conteúdos observou-se a predominância da mecânica nos três blocos de análise. Física térmica foi o segundo conteúdo mais cobrado, seguido por ondulatória, eletromagnetismo, óptica geométrica e física moderna, que esteve presente em apenas 0,66\% das questões de todas as provas analisadas, como pode ser visualizado na Fig. 7.

Cabe salientar que as questões que exigem cálculos e formalismos matemáticos para sua resolução constituem a grande maioria em todos os anos. Foi observado nos anos de 2000, 2002 e 2005 um decréscimo dessas, porém nos últimos anos analisados, referentes ao terceiro bloco de análise, ocorreu um acréscimo significativo. O gráfico a seguir mostra as médias percentuais, de cada bloco de análise, perante a exigência para a resolução da questão.

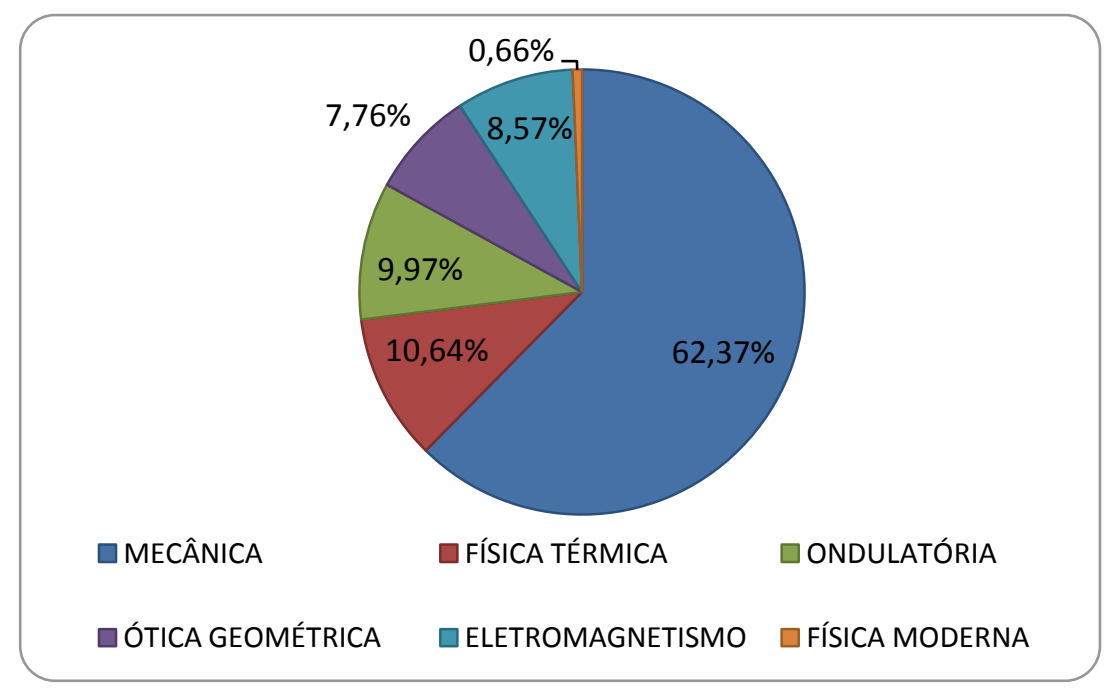

Fig. 7 - Gráfico de distribuição dos conteúdos das questões das provas da OBF de 1999 a 2013. 


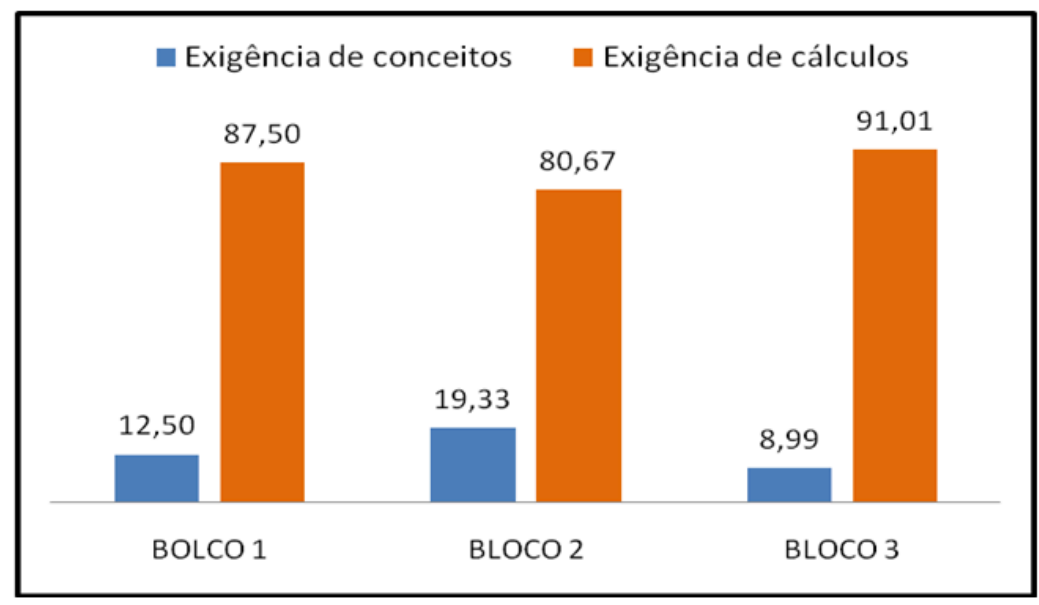

Fig. 8-Gráfico com os percentuais de questões que exigiam a utilização de cálculos ou de conceitos para sua resolução segundo cada bloco de análise.

Apesar do grande número de questões que exigem a utililização de formalismos matemáticos, é necessário destacar que muitas delas só poderiam ser resolvidas se o estudante tivesse conhecimentos sobre o conceito físico em questão, para que a partir desse, pudesse fazer associações ou deduções para a utilização do formalismo matemático necessário. Mesmo assim, verifica-se a necessidade de maior valorização de questões com focos em conceitos físicos e suas relações com atividades cotidianas. A inserção de questões com essa identidade nos instrumentos de avaliação pode auxiliar a diminuir a conotação demasiadamente matemática atribuída ao ensino de física.

Os resultados obtidos não permitem predizer como será o modelo de prova adotado para os próximos anos, mesmo sendo evidente que as últimas provas da OBF têm tido um estilo diferenciado em relação aos anos anteriores, com mais contextualização na formulação das questões. Se for seguida a tendência "temática" das provas, pode-se pensar nos jogos olímpicos no Brasil em 2016 ou nos setenta anos da bomba de Hiroshima em 2014, porém as sugestões para esses temas são inúmeras. Essa evolução no modelo de prova está de acordo com o que está escrito nos Parâmetros Curriculares Nacionais (2002, p.144) que trazem orientações a respeito da necessidade de se implementar a contextualização e interdisciplinaridade no processo educacional.

O conhecimento das características das provas olímpicas pode servir de orientação para atividades subsidiadas pela escola no que tange o estudo dos alunos para a participação na OBF.

Os professores de física, ao se inteirarem sobre os conteúdos das provas da OBF, podem usufruir desses, organizando bancos de questões com potencial para serem utilizadas em aulas, avaliações, gincanas escolares, etc. 
Além disso, os resultados deste trabalho podem auxiliar os estudantes interessados tanto no conhecimento do processo e dos modelos de prova utilizados quanto no direcionamento para o estudo dos ramos da física.

Almeja-se que esse trabalho possa incentivar a reflexão dos professores do ensino médio sobre o potencial que as provas da OBF possuem no processo de ensino aprendizagem, além de incitar a instauração de uma cultura de utilização das atividades da OBF no contexto escolar.

\section{Referências bibliográficas}

BRASIL. MINISTÉRIO DA EDUCAÇÃO. SECRETARIA DE EDUCAÇÃO MÉDIA E TECNOLÓGICA. PCNs+ Ensino Médio: orientações educacionais complementares aos Parâmetros Curriculares Nacionais. Ciências da Natureza, Matemática e suas Tecnologias. Brasília: MEC, SEMTEC, 2002. 144 p.

ERTHAL, J. P. C. et al. Análise das provas das Olimpíadas Brasileiras de Física para realização de tutorias específicas nas escolas parceiras do projeto PIBID no município de AlegreES. In: SIMPÓSIO NACIONAL DE ENSINO DE FÍSICA, 20, 2013, São Paulo. Atas... São Paulo: SBF, 2013. Disponível em:

<www.sbf1.sbfisica.org.br/eventos/snef/xx/sys/resumos/T0960-1.pdf>. Acesso em: 10 fev. 2014.

MARIN, L. R.; PINO JUNIOR, A. D. Olimpíada Paulista de Física - Questões resolvidas e comentadas. 1 ed. São Paulo: Editora Livraria da Física, 2008, 232 p.

OSTERMANN, F.; REZENDE, F. Olimpíadas de ciências: uma prática em questão. Ciência \& Educação, v. 18, n. 1, p. 245-256, 2012.

SOCIEDADE BRASILEIRA DE FÍSICA. Regulamento: objetivos. Disponível em: <www.sbf1.sbfisica.org.br/olimpiadas/obf1999/main.htm>. Acesso em: 14 fev. 2014.

VIANNA, J. D. M. et al. Olimpíadas de Física. Revista Física na Escola, São Paulo, v.1, n.1, 2000 .

VIANNA, J. D. M.; SIQUEIRA, F. F. Olimpíadas de Física. Revista Física na Escola, São Paulo, v. 5, n. 2, p. 29-30, 2004. 